\title{
Política de cotas no Brasil: política social?
}

\author{
Janete Luzia Leite \\ Universidade Federal do Rio de Janeiro (UFRJ)
}

\section{Política de cotas no Brasil: política social?}

Resumo: Este artigo discute as políticas de ação afirmativas - notadamente a política de cotas - como mais uma estratégia do capitalismo em seu estágio atual para passivizar a classe trabalhadora na luta pela ampliação de direitos sociais. Parte da hipótese de que segmentos historicamente explorados têm a sua não integração na sociedade como resultante da "questão social”, e não de determinações particularistas. Para tanto, utiliza a teoria social crítica para analisar a emersão e o evolver das políticas sociais no Brasil e de que forma estas se metamorfoseiam sob a égide do governo Luís Inácio Lula da Silva. O sistema de cotas étnico-raciais para o ingresso no ensino superior público é aqui contrastado com a defesa de políticas públicas de caráter universal. Conclui que a assistencialização das políticas sociais é mais um instrumento para eliminar a luta política dos trabalhadores e escamotear as expressões da questão social.

Palavras-chave: Políticas sociais. Ações afirmativas. Cotas. Brasil.

\section{Quota Policy in Brazil: Social Policy?}

Abstract: This article discusses affirmative action policies - notably quotas - as a current strategy of capitalism to pacify the working class in the struggle for expansion of social rights. It begins with the hypothesis that the lack of integration into society of historically exploited segments is a result of the "social question" and not of particular determinations. It therefore uses critical social theory to analyze the emergence and development of social policies in Brazil and understand in what way they were transformed under the aegis of the government of President Luís Inácio Lula da Silva. The system of ethnic and racial quotas for entrance into public higher education is contrasted here with the defense of public policies of a universal character. The article concludes that social policies focused on providing assistance are tools designed to eliminate the political struggle of workers and hide social expressions.

Key words: Social policies. Affirmative action. Quotas. Brazil. 


\section{Explorando caminhos}

Tomando como ponto de partida o final dos anos 1970 , momento em que as camadas populares ressurgem na cena política nacional, organizadas em sindicatos e em movimentos populares, pode-se observar a trajetória percorrida por segmentos hoje autodenominados oprimidos ${ }^{1}$, estejam eles articulados em grupos, sejam eles intelectuais atuando na academia.

Nesse percurso, o período compreendido entre o final dos anos 1970 e o final da década de 80 marca o (res)surgimento de novos movimentos sociais no Brasil, lutando por conquistas no campo dos direitos sociais e pelo retorno da democracia no país. Norteados pelos paradigmas da modernidade, adotando um esforço militante na construção da alternativa socialista. Isso, apesar da influência dos movimentos que despontaram no ocidente europeu e no norte da América, na década de 1960 , que eram críticos aos ideais modernos. Prevaleceu a coesão em torno do que era considerado como bem comum; ou o que, em nome do direito, deveria ser direito de todos na caminhada em direção à edificação de uma sociedade justa e igualitária e da emancipação humana.

Nessa trajetória, verifica-se a existência de um atalho por onde seguiram setores desta intelectualidade e alguns grupos que estabeleceram um reposicionamento político, na medida em que foram transformando estes novos movimentos em um "novíssimo movimento". Mas é também um reposicionamento ideológico, uma vez que acaba transferindo aquilo que estava no campo da modernidade para o espaço hoje ocupado pelo pósmoderno. Este contexto desloca a presença histórica destes grupos na sociedade brasileira - uma situação antes compreendida como inscrita na própria luta de classes - marco da questão social ${ }^{2}$-, para colocála no que vem a ser chamado de "nova questão social" (CASTEL, 1993; ROSANVALLON, 1995), característica de uma suposta sociedade sem classes.

Ao raiar dos anos 1990, uma onda "modernizadora" impõe nova direção à sociedade brasileira. Esse processo de mudança social é parte do cenário de "alterações contemporâneas por que passa o capitalismo que Mandel chamou de tardio, com a substituição (de acordo com a terminologia de Harvey) de um padrão de acumulação rígida por um de 'acumulação flexível'" (PAULO NETTO, 1996, p. 24). Essas alterações se espraiam em todas as áreas da vida da sociedade brasileira e, no que diz respeito aos movimentos sociais, reflete-se em uma nova forma de organização e concepção social. Surge o que Abramo (1994) denominou de "novíssimos movimentos sociais", que não buscam atingir as causas sociais dos problemas que atacam, ainda que, às vezes, as reconheçam ou explicitem. Antes, trabalham so- bre bases do campo do emocional e do afetivo, mais do que no plano racional, a fim de pressionarem a implementação de políticas sociais que privilegiem os segmentos por eles abarcados. Assim, suas ações se colocam no âmbito da elevação da autoestima, considerando uma subjetividade "rasa", sem trabalhar as condições objetivas concretas que a engendram. Seus alvos são metas factíveis e, de preferência, quantificáveis, como por exemplo, cotas étnico-raciais para o ingresso ao ensino superior ou ao serviço público. Colocam-se, portanto, no centro da pósmodernidade, na medida em que se impregnam de

Correntes que negam a existência de estruturas e conexões estruturais, bem como a própria possibilidade de 'análise causal'. Estruturas e causas foram substituídas por fragmentos e contingências. Não há um sistema social (como, por exemplo, o sistema capitalista), com unidade sistêmica e 'leis dinâmicas' próprias; há apenas muitos e diferentes tipos de poder, opressão, identidade e 'discurso'. [...] Os pós-modernistas enfatizam a 'diferença': identidades particulares, tais como sexo, raça, etnia, sexualidade; suas opressões e lutas distintas, particulares e variadas (WOOD, 1999, p. 37).

Dessa forma, encontramos hoje aqueles setores dos movimentos sociais e da intelectualidade supraelencados, tomando o atalho para novas posições, que passaram a ser apresentadas como as mais "favoráveis" para os segmentos oprimidos.

A existência de desigualdades em nossa sociedade é real, principalmente para estes grupos que, no geral, possuem menos escolaridade, salário, saúde, emprego e moradia. Entretanto, a superação dessas desigualdades não passa pela afirmação de preceitos constitucionais, que servem de base para uma concepção (neo)liberal de sociedade, e que acabam por escamotear a ausência de direitos a todos. Não é suficiente basear a luta contra o preconceito e a discriminação que atingem a estes setores em um imperativo moral que se estabelece exaltando a particularidade.

Seguindo este raciocínio, a hipótese a ser explorada neste texto é a de que a integração (ou não integração) destes grupos na sociedade brasileira é fruto da questão social, e não dessas determinações que, na atualidade, procuram estabelecer um novo posicionamento nessa busca de integração. Assim, as atuais iniciativas - a que se dá o nome de políticas sociais - que, a pretexto da "igualdade" e da "justiça social", buscam minimizar os efeitos da discriminação por meio de medidas de exceção, na verdade invertem os termos da questão, sem resolvê-la. Estas políticas, outrossim, configuram uma "discriminação ao contrário", que atende tão somente às diretrizes impostas pelo modelo neoliberal e seus organismos financeiros inter- 
nacionais, induzindo saídas individuais e negando a dimensão coletiva da sociabilidade.

A fim de explorar esta assertiva, o caminho a ser percorrido inicialmente explicitará a relação medular entre questão social e política social para, então, verificar de que maneira a proposta de universalização desta última derivou em políticas particularistas, denominadas Políticas de Ação Afirmativa (PAA) e a sua configuração no caso brasileiro. Para tanto, o exemplo utilizado será o da reivindicação de cotas étnico-raciais para o ingresso de negros na universidade pública.

\section{Questão social e políticas sociais}

As políticas sociais têm sua gênese no final do século 19, a partir da emersão da chamada questão social, espraiando-se internacionalmente no século 20 como o resultado da consolidação da transição do capitalismo concorrencial para o monopolista (PAULO NETTO, 1992; BEHRING; BOSCHETTI, 2006). Neste sentido, a atenção à questão social na sociedade capitalista vem sendo pensada como uma forma de regular os conflitos com a intenção de obter a legitimação da ordem e o consenso social, dando respostas a algumas das reivindicações dos setores subalternos que possam colocar em perigo a ordem capitalista e a necessária coesão social.

É evidente que as políticas sociais não podem ser analisadas exclusivamente a partir do Estado (como mecanismo de dominação dos grupos no poder), nem tampouco unicamente a partir da sociedade civil (como produto das pressões e vindícias dos setores subalternos frente ao Estado). Devem, sim, ser compreendidas como uma relação, como uma mediação entre o Estado e a sociedade civil, depositários de uma dupla característica de coerção e consenso, de concessão e conquista (PASTORINI, 1997).

Para que as políticas sociais pudessem ser

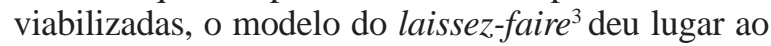
protecionismo estatal. O Estado foi chamado a intervir na economia e um pacto social foi estabelecido com a classe trabalhadora. Entrava em cena o Estado de bem-estar social, baseado no modelo fordistakeynesiano, que inaugurou os chamados "30 anos gloriosos do capitalismo". É óbvio que este modelo deve ser considerado à luz de cada país no qual se instaurou. No Brasil, nas lúcidas palavras de Francisco de Oliveira (2003), o que tivemos chegou muito mais perto do que poderíamos chamar de um Estado de malestar social devido à formação político-social do país.

Em face de uma nova crise internacional do capitalismo, nos anos 1970, a resposta encontrada foi a instauração do neoliberalismo, baseado principalmente no enxugamento do Estado no que diz respeito às políticas sociais; no solapamento dos direitos sociais, conseguidos no que concerne a modelos de proteção social no trintenário anterior; e na desorganização dos trabalhadores. Paulatinamente, as experiências de condução política neoconservadoras retiram da órbita do Estado as funções de proteção social consideradas "ineficientes" do ponto de vista mercantil, buscando outros "responsáveis" para sua produção e administração. Desta forma, as crises e a crítica do Estado permitiram o avanço da tese liberal-conservadora no campo das políticas sociais, reforçando o processo de reforma do Estado mediante a justificativa da necessária redução da esfera pública.

Tudo isso tem como chão uma crise cronificada, que manifesta um pico de exasperação do movimento social; o tecido social se crespa e está quase rompido. Está-se falando de um tensionamento que vai aumentando lentamente até se incorporar ao cotidiano, não causando mais qualquer reação; tornase natural. As resultantes mais visíveis encontram eco nos movimentos dos trabalhadores (uma enorme dominância corporativista) e no conjunto do movimento social (uma atomização e uma pulverização absolutas). Simplesmente joga-se na fragmentação e transfere-se para organismos da ressignificada sociedade civil o ônus de projetos estrategicamente dirigidos pelo Estado, entrando aí um soberano desprezo por este.

Há uma expansão mundial da "desproteção social". O desemprego estrutural (fomentado principalmente pela reestruturação produtiva) e o aumento da pobreza e da miséria sociais (causados pela conjugação de desemprego, retirada de direitos e demolição de políticas sociais), provocam a ascensão de uma franja social que começou a ser considerada "desnecessária" ao capital, ou seja, não se inseriria na economia - seja ela formal ou informal. Esta franja social manifesta-se por meio de uma horda de neofamélicos e neomiseráveis, que não só colocam em xeque as maravilhas propaladas pelos arautos do neoliberalismo, como também ameaçam a sua continuidade, pois são a prova cabal da falência do novo modelo. São estes os segmentos mais pauperizados da sociedade e, não raro, aqueles também mais historicamente marginalizados. Novamente, a subjetividade dos trabalhadores precisa ser capturada e reconfigurada a partir de um padrão de individualismo no qual a luta de classes deve ser obscurecida, dando lugar a um estranhamento interclasse.

Sem desconhecer as especificidades de cada país, essa década marca um giro extremamente importante em nível mundial, enquadrado pelo avanço da ofensiva neoliberal em duas das suas principais características: o desmonte da responsabilidade pública em relação às grandes problemáticas sociais e a proposta de Estado mínimo. Contudo, em todos os quadrantes do planeta, é notório que a ofensiva neoliberal exige a reconfiguração do Estado. 
Para tanto, instaura-se um período de investida do pensamento conservador que não encontra precedentes antes dos últimos 30 anos do século 20 . O conservantismo consegue de tal forma obnubilar o real, que o traveste de uma irracionalidade pós-moderna, caucionando o fragmentário, o caótico, as novas "identidades sociais" e os "novos movimentos sociais". O capitalismo incorpora essa irracionalidade. Isto porque o problema é superar não uma racionalidade, tomada como tal, mas uma racionalidade que foi instrumentalizada pelo capital. Mas isto significa colocar em questão a ordem vigente, e é próprio dos pensadores pós-modernos caucionar a ordem vigente. Porque sustentar o fim ou a exaustão do modelo societário precedente é sustentar também todo um bloco sociocultural que foi extremamente funcional ao capital.

A conjugação destes elementos implica em uma nova sociabilidade, que se inicia com o redimensionamento da classe trabalhadora e envolve o aprofundamento da questão social.

\section{Políticas sociais sob a égide do neolibera- lismo no Brasil}

Até a década de 1980, na maior parte dos países latino-americanos, foi o Estado, por meio de suas políticas sociais, quem assumiu prioritariamente a atenção das sequelas da questão social. É a partir deste decênio que, em um claro ataque aos princípios do Estado social, os neoliberais promoveram a redução de qualquer intervenção estatal no interior da dinâmica do mercado, em particular aquelas portadoras de mecanismos democráticos que pudessem controlar o movimento do capital. Não há um aumento significativo, em nenhum país latino-americano, do mercado de trabalho formal. Cresce a informalidade. $\mathrm{O}$ que se assiste, dos anos 1980 para frente, é um estímulo claro à organização dos informais.

Uma das transformações mais importantes foi a redução da ação reguladora do Estado. Os estrategas neoliberais argumentam, tout court, que somente um Estado mínimo pode propiciar uma administração racional, que incorpore os diversos segmentos sociais aos bens socialmente produzidos por meio da integração ao mercado. Argumentam que a ótica patrimonialista e extremamente onerosa do Estado (especialmente o Estado de bem-estar) é, na verdade, ineficaz, e produz efeitos contrários aos desejados, criando desigualdades onde supostamente se pretendia obter uma maior equidade.

Assim, entra em curso a tendência a transformar os regimes universais de proteção social em uma particularização de benefícios sociais. Tem-se, por um lado, a redução e a focalização da ação estatal para aqueles casos mais imediatos e urgentes (consubstanciando o princípio da subsidiariedade do Estado); e, por outro lado, a privatização e a consequente transformação em mercadoria dos serviços sociais a serem adquiridos no mercado pelo "cidadão consumidor" (MOTA, 2005). Essas mudanças foram comandadas pelo Consenso de Washington, que estabeleceu regras a serem implementadas nos países periféricos para enfrentar a crise do capitalismo.

A pobreza, caracterizada pelas franjas anteriormente aludidas, passa a ser vista como algo inarredável e ineliminável, posto que faz parte do ordenamento social. Desta forma, há que mantê-la em níveis suportáveis, ou seja, há que se combater a pobreza absoluta ${ }^{4}$. É esta que é posta em condições de ser erradicada. O fundamental passa a ser "controlar a pobreza".

Neste contexto, é incentivado o surgimento de segmentos sociais, agrupados quer por suas "identidades", quer por suas "necessidades" e "diferenças", que começaram a ganhar proeminência para a intervenção de políticas sociais específicas para cada um destes segmentos. Seguindo o receituário neoliberal e das agências financeiras internacionais multilaterais, estas políticas não mais seriam conduzidas exclusivamente pelo Estado, e sim pela "sociedade civil”, pelas organizações não governamentais (ONG), pelas empresas e pelo denominado Terceiro Setor.

Assim, o combate à pobreza absoluta se dá por meio de políticas denominadas de "ações afirmativas" (PAA).

\section{Políticas de ação afirmativa à brasileira}

No Brasil, o pioneirismo do Partido dos Trabalhadores (PT), em relação aos seus irmãos sul-americanos, no tocante à eleição de governantes oriundos de partidos de esquerda, materializado na legitimidade conferida nas urnas, em outubro de 2002, à candidatura de Lula da Silva, não impediu uma política de aprofundamento das medidas de caráter neoliberal. E isto se verificou, notadamente, no que diz respeito à continuidade de uma política macroeconômica absolutamente favorável ao capital financeiro - tão cara aos governos anteriores, aos quais o PT, agora no governo, criticou sempre exacerbada e enfaticamente (LEITE et al., 2008).

Eleito pela esperança de 53 milhões de brasileiros para levar adiante um projeto alternativo às medidas ditadas pelos organismos internacionais (FMI, BM etc.) e pelo governo dos Estados Unidos, Lula da Silva contemplou a população brasileira com um conjunto de ações que, hoje, surpreendem até os seus formuladores originais (COGGIOLA, 2004). Esta foi a opção do PT, anunciada desde antes das eleições: honrar todos os contratos com o capital. Nenhum contrato foi honrado com os trabalhadores (PAULO NETTO, 2004). O PT chega, portanto, ao governo, da mesma forma como 
se executa uma melodia ao violino: segura com a mão esquerda e toca com a direita.

Reformas que não medraram no governo Fernando Henrique Cardoso (FHC) foram encaminhadas açodadamente no primeiro mandato do governo petista. Nesse sentido, a reeleição de Lula da Silva não aportou, no todo, maiores novidades - internas ou externas.

No processo eleitoral, o Bolsa Família foi a principal moeda de troca, notadamente entre os segmentos mais pauperizados da população. Aliás, as políticas assistencialistas foram cuidadosamente ministradas aos brasileiros, ao mesmo tempo em que políticas macroeconômicas de corte o mais ortodoxo possível os empobrecia. Produziu-se, assim, uma química altamente apassivadora de prováveis conflitos advindos de uma horda de miseráveis (DIAS, 2006). Some-se a isso um discurso messiânico de péssima envergadura e tem-se, facilmente, a maior parte dos votos que reelegeram Lula da Silva.

Destarte, esse assistencialismo prima: não somente retira, paulatinamente, toda e qualquer responsabilidade do Estado, no que diz respeito ao financiamento e à gestão das políticas sociais, como também joga, pesadamente, essa responsabilização sobre as famílias e comunidades (outorgando-lhes, ainda, uma boa dose de culpabilização pela sua própria situação de penúria social).

Garante-se, assim, a continuidade (sempre aprofundada) do projeto inicial de Fernando Collor (que desorganiza o Estado), assumido por FHC (que o desmonta) e que, provavelmente, será coroado por Lula da Silva (cuja missão é redesenhar o Estado).

Portanto, o fenômeno que se delineia e consolida, nos últimos 8/10 anos, é a assistencialização do conjunto das políticas sociais, ou seja, essas políticas, antes universalistas, passam a assumir um cariz nitidamente assistencialista, focalizado, pontual, segmentado, clientelístico e descentralizado (descentralizase a tarefa, e não o recurso) (PAULO NETTO, 2004; IAMAMOTO, 2007). Trata-se, antes de mais, de ordená-las segundo as prioridades que podem tornar mais perigosas as classes perigosas.

Nenhum dos programas que, hoje, está em voga, oferece qualquer porta de saída. Apresentar esse tipo de solução como algo mais que emergencial, não é apenas um equívoco. É muito mais que isso: é uma orientação política de natureza claramente ideológica. Dá-se aos pobres o seu lugar para conservá-los como tais.

Neste quadro de assistencialização do conjunto das políticas sociais, o que se tem é uma cronificação do combate à pobreza. E, na medida em que este conjunto se cronifica e se transmuta em políticas sistemáticas, os resultados para a sociedade brasileira e a sua grande massa de trabalhadores - empregados ou não - serão deletérios.
É justamente por operar neste mosaico ideológico que as PAA, notadamente a política de cotas (seja qual for o seu naipe), prometem, em nome de "reparações sociais", uma suposta mobilidade social ascendente adquirida a partir de uma desigualdade de gênero, etária, étnica etc. Tudo se transforma em um problema do idoso, da mulher, do jovem, do índio... Ou seja, nulifica-se a classe social, porque tudo passa a derivar de grupos específicos, que são descolados de uma totalidade social (LEITE, 2008).

\section{Um caminho - a luta coletiva}

Em 1995, foi realizada, em Brasília, a I Marcha Zumbi dos Palmares contra o Racismo, pela Cidadania e pela Vida. Entre os anos 2000 e 2001, ocorreu uma frenética mobilização, que culminou com a participação na III Conferência Mundial das Nações Unidas contra o Racismo, Discriminação Racial, Xenofobia e Intolerância Correlata (Durban, África do Sul), que deixou como saldo um processo que agora auge com os manifestos pró e contra a adoção do sistema de cotas (VITÓRIA, 2004, 2007).

Este é o resultado mais visível do processo de organização do movimento negro no Brasil, sobre o qual será feita uma breve digressão.

Em meados dos anos 1970, o regime militar começa a dar mostras de exaustão. Presencia-se o ressurgimento da sociedade civil, a partir de militantes das Comunidades Eclesiais de Base, vinculadas à Igreja Católica, sensível às organizações de esquerda e sindicatos. Articula-se uma rede de movimentos populares urbanos que buscam representar as mais diferentes reivindicações em espaços como fábricas, associações de moradores, movimentos por moradia, contra o aumento do custo de vida, movimento estudantil, entre outros. E aí se encontram, também, as organizações do movimento negro. Em 1978 é fundado o Movimento Negro Unificado contra a Discriminação Racial.

Em um primeiro momento, as organizações sociais e sindicatos buscam estabelecer uma posição de autonomia frente a partidos políticos, instituições, igrejas etc., sendo frequentes as tensões entre os movimentos e partidos ou entre os movimentos e a Igreja.

$\mathrm{Na}$ relação destes movimentos com o Estado, o potencial deste último como indutor de demandas, acaba por ficar oculto no discurso das organizações, que destacam a autonomia e o caráter antiEstado dos movimentos sociais, configurando uma relação de negação do Estado ditatorial e de oposição ao governo militar. O Estado procura garantir alguma legitimação pelo consenso passivo e passa a responder às reivindicações dos movimentos mediante a efetivação de políticas sociais nas áreas de saúde, saneamento básico, sistemas de transporte, dentre 
outras, o que redunda na ampliação das demandas populares. Essas medidas, já no início da década de 1980, em função da crise econômica e das manifestações de ação direta, encontram um Estado incapaz de dar respostas rápidas aos anseios dos setores sociais atingidos pela recessão.

No enfrentamento desses dilemas, a sociedade brasileira vai apurando a construção de um novo padrão de organização, que ganha um corpo político. Pessoas antes sem nenhuma participação política surgem em cena com uma disposição militante diferente daquela existente na lógica populista anterior. É fundado o PT que, no leque de partidos políticos gerados pela reforma partidária de 1979 , viria a representar um canal institucional de participação das camadas populares que para ele acorreram por meio dos novos movimentos sociais e sindicais. É também criada a Central Única dos Trabalhadores (CUT), em 1983, articulando as forças do novo sindicalismo, nascido, principalmente, nas greves do $\mathrm{ABC}$ paulista.

No PT e na CUT, entidades construídas como instrumentos da luta de classes, a geração de militantes negros oriunda dos anos 70 encontra seu espaço para continuar desenvolvendo sua luta antirracial.

Nesse cenário, as questões trazidas pelos militantes negros eram vistas como mais uma das consequências da divisão da sociedade em classes sociais, inerente ao capitalismo e, desta forma, inseridas no que, desde o século 19, conhece-se como questão social.

Até o final da década de 80 , percebe-se que a mobilização política da população negra logrou alcançar espaços de participação política institucional por meio dos Conselhos de Participação e Desenvolvimento da Comunidade Negra, órgão que surge primeiro em São Paulo, sob o governo de Franco Montoro, e que depois servirá de modelo aos demais governos estaduais. Outra mostra do avanço da luta negra é o fato de a existência da discriminação racial ter sido admitida, no interior do processo de elaboração da Constituição de 1988, não como contravenção penal (como aparecia na Lei Afonso Arinos, de 1951), mas sim, tipificada como crime inafiançável e imprescritível.

Toda esta construção começa a ruir quando, inicialmente com o Comunidade Solidária, de FHC, e posteriormente mediante a implementação, a granel, das PAA, pelo governo de Lula da Silva, os setores menos politizados do movimento negro anteviram formas mais céleres e menos "trabalhosas" (como a luta coletiva) para alcançarem seus objetivos. O negro, de segmento historicamente explorado, passa a ser portador de uma dívida histórica, hipotecada pelo seu caráter de opressão. O negro, doravante, não mais pertence à parcela dos explorados pelo capital - portanto, "igual" a todos aqueles pertencentes à classe trabalhadora -, mas descola-se dos trabalhadores, para se tornar "merecedor" de políticas de exceção, porque é "diferente" dos demais. Que os outros trabalhadores busquem seus espaços específicos, quer para terem acesso aos estudos, quer para conseguirem um lugar no mundo do trabalho. Instala-se o reinado do "farinha pouca, meu pirão primeiro".

Neste encadeamento, o ingresso nos cursos de nível superior apresenta-se como a mais rápida oportunidade para a ascensão social. Troca-se o diploma de "doutor" pelo silêncio das reivindicações por uma educação integral, formadora e propedêutica desde a infância. A universidade resolverá os problemas de antanho. Verdadeiro elixir de catuaba.

$\mathrm{O}$ fato de que o ingresso no mercado de trabalho é um problema estrutural não importa; será resolvido com a implementação de novas cotas, preferencialmente para o setor público (mais "garantido").

Para o alcance destes objetivos, não interessa a sua forma final, não interessa o conteúdo das discussões. A máxima de que "o fim justifica os meios" é posta em movimento, n'importe qui, n'importe quoi. Assim, trabalhador passa a desconhecer trabalhador, a partir da sua cor de pele, de seu gênero, de sua idade.

\section{Outro caminho - ... e continuaremos negros ${ }^{5}$}

A implementação do sistema de cotas raciais para $\mathrm{o}$ ingresso de estudantes negros no ensino superior e a aprovação do Estatuto da Igualdade Racial são, hoje, os principais temas colocados pela população negra na pauta de discussão da sociedade brasileira.

É notória a existência de desigualdades a serem enfrentadas pelos negros que, nesta sociedade, possuem - na média geral - menos escolaridade, salário, saúde, emprego e moradia que os brancos e asiáticos. Entrementes, não é suficiente ancorar a luta contra o preconceito e a discriminação que atingem a população negra brasileira com um imperativo moral que se estabelece exaltando a particularidade.

As especificidades precisam ser vistas também no que possuem em comum e, por este prisma, é necessário considerar que as dificuldades encontradas pelos estudantes negros são as mesmas enfrentadas por estudantes pobres, filhos de trabalhadores não negros, que chegam às portas da universidade $\mathrm{e}$ não conseguem adentrá-las, em função de uma educação formal deficitária, oferecida por uma rede pública desqualificada pela falta de investimentos dos sucessivos governos. Também eles são componentes de um segmento da sociedade que vive em precárias condições socioeconômicas. Mesmo aqueles ferrenhos defensores das cotas - que por vezes incorrem no equívoco de confundir racismo com acesso - reconhecem esta realidade: 
[...] Afinal, sejamos honestos, bons colégios, cursos de língua estrangeira, acesso às salas de cinema, teatro e artes, colônias de férias, viagens familiares e escolares, aquisição de jornais, revistas, material didático de bom e moderno conteúdo, manejo regular de equipamentos como computador e acesso a redes de informação disponíveis pela internet, ambiente domiciliar dotado de infraestrutura adequada à realização das tarefas escolares é uma questão de classe e não, exata ou exclusivamente, de mérito (CICONELLO, 2008, p. 2-3).

Está colocada, desta forma, a vigência da luta de classes, que só será superada por uma ação anticapitalista que vise construir um projeto societário que, alternativo ao capitalismo, possa estender o direito a todos sob uma lógica centrada no Homem, buscando sua emancipação.

Como já exposto, é justamente na área da Educação que as PAA têm obtido maior eco. É também nela que não se encontra, em seu cerne, uma política que responda aos interesses, e muito menos aos anseios da classe trabalhadora. O caráter ambíguo desta proposta pode estar relacionado ao fato de que tais ações não se caracterizam como uma política pública de cunho universal, porque diz promover o acesso de parcela da população tradicionalmente discriminada sem, no entanto, capacitá-la para desenvolver plenamente suas potencialidades, e muito menos prever mecanismos para isso (GLÓRIA, 2006). Afinal, que tipo de mecanismos estão sendo criados pelos defensores destas ações no interior das universidades para a manutenção de estudantes cotistas até a conclusão de seus cursos superiores? (LEITE, 2008). A não ser que se deseje chamar programas como o Afroatitude - Programa Integrado de Ações Afirmativas para Negros, do Ministério da Saúde ${ }^{6}$ - de Política de Assistência (ou permanência) Estudantil.

Esse tratamento "preferencial" destinado àqueles que historicamente foram marginalizados, coloca em questão, além dos aspectos citados, vários outros relacionados ao acesso de grupos específicos (não só dos negros), uma vez que apresenta um caráter contraditório: ao mesmo tempo em que propagandeia a ampliação da oportunidade e ascensão social, reforça estereótipos já existentes de falsas "inferioridades". Isto porque, por meio da adoção de um percentual numérico, cujo objetivo principal é garan- tir a presença de parcela da população socialmente discriminada em diversas esferas da vida social - no caso em tela, na universidade -, a política de cotas, lamentavelmente, acaba reforçando uma pretensa incapacidade desses indivíduos, posto que se baseia na utilização do desprestígio como critério específico. A decisão política de "reparar" os danos sofridos por segmentos sociais não deve implicar em um conjunto de políticas ditas "afirmativas". Nem, tampouco, a luta em defesa de políticas específicas que acarretem a subestimação da necessidade de se promover realmente uma luta em benefício destes grupos, até porque este argumento mistifica e escamoteia a verdadeira gênese: a desigualdade de classe que se deseja ver perpetuada. Assim, essa inclusão se daria permanentemente em patamares subalternos à ordem e à classe dominante, anestesiando a percepção do servilismo e da desigualdade. Teoricamente, essas políticas surgem para privilegiar segmentos discriminados, mas na prática acabam dispensando um tratamento desigual aos "desiguais", na medida em que buscam promover a igualdade de oportunidades por meio de ações igualmente discriminatórias que, consequentemente, caracterizam (ou até mesmo reforçam) a inferioridade destes segmentos.

No estágio atual do capitalismo, as PAA estão muito mais próximas de esmolas oficializadas, com o auxílio fabuloso da mídia convencional, do que qualquer outra compensação. De políticos a empresários e artistas, todos pedem esmolas em nome das populações sobrantes para o capital (SOUZA et al., 2006), tamanha a sua competência para incorporar os anseios dos trabalhadores para sobreviver, e de encontrar, no seio da classe trabalhadora, serviçais ávidos e aptos ao seu chamamento.

\section{Direção a seguir - sem atalhos}

Foi colocado em curso um amplo conjunto de "formas alternativas" de encaminhar os programas sociais, que passam a ocupar espaços onde antes predominava o Estado. Os serviços sociais enfrentam uma situação extremamente crítica, agravada de forma dramática pelas sucessivas crises e com a interferência das medidas reformistas que desorganizaram as práticas anteriores sem colocar nada em seu lugar. Entretanto, deve-se ter presente que uma parte 
importante dessas novas formas de políticas para atender o social - e escamotear as expressões da questão social - materializa-se como "instrumentos para eliminar o caráter da luta política, convertendo os conflitos e tensões sociais em expressões vazias de sentido transformador, com a intencionalidade de convertê-las em expressões neutras".

As políticas sociais, travestidas doravante em "programas para grupos historicamente oprimidos", mediante as PAA, funcionam exatamente como instrumento de divisão da classe trabalhadora, a partir de sua característica residual, pontual e fragmentadora. Perde-se, com isso, o horizonte da luta coletiva. Além disso, a focalização despolitiza as políticas, tirando o foco da totalidade do real, naturalizando, banalizando e - ato contínuo - criminalizando as refrações da questão social, transformando-as em expressões individuais.

É evidente que o combate a essa lógica demanda relações com a dinâmica do movimento das classes sociais e dos movimentos sociais, que são interlocutores extremamente significativos. Portanto, na trilha do método já sobejamente empregado, estes são interlocutores que devem ser cooptados ou, caso necessário, corrompidos. Mas é preciso lembrar duas coisas: primeiro, que o movimento social é capaz de ajudar e promover a emancipação política. Mas segundo - movimento social nenhum promove a emancipação humana. Se os movimentos sociais não encontrarem uma outra instância, uma instância de universalização de interesses sociais, serão corporativizados. Isto porque é notório que os movimentos e grupos que militam nestas áreas têm se mostrado corporativos e restritos em suas demandas e formas de encaminhamento das lutas sociais, neles predominando uma visão instrumental, moral e conjuntural do Estado, das políticas sociais e das instituições que eles pretendem influenciar para orientar suas ações. Sua ótica não é equitativa e/ou universalista, mas particularista, e sua capacidade de mobilização está marcada pelo apelo emocional.

É por isso que as PAA, além de não serem políticas sociais, também não representam sequer a possibilidade de uma transição para políticas universalistas. A consequência imediata é o enfraquecimento da luta por novos direitos e a fragilização daqueles já conquistados. Esse é só um pálido quadro do peso das singularidades e das particularidades na esfera onde só há avanço possível no marco da universalização. A reversão deste quadro pressupõe a articulação das diferentes esferas da sociedade em uma perspectiva de ampliação e politização do debate, a fim de que o discurso apassivador e anestesiante não encontre eco.

Somente recuperando a matriz universalista e a luta coletiva, materizalizada na consciência de "classe para si", os horizontes presentes poderão transformar-se em um futuro possível, quando então as "massas" sai- rão de um contexto de espera de "benesses", para uma realidade de transformação histórica.

\section{Referências}

ABRAMO, P. Sociedade: velhos partidos e novíssimos movimentos. Teoria e Debate. São Paulo, Fundação Perseu Abramo, n. 24, p. 27-31, mar./abr./maio, 1994.

BEHRING, E.; BOSCHETTI, I. Política social fundamentos e história. São Paulo: Cortez, 2006.

BRASIL. Ministério da Saúde (DST/Aids). Brasil Afroatitude: primeiro ano do programa. Brasília, DF, 2006. (Série Anais, Seminários e Congressos, n. 6).

CASTEL, R. Les metamorphoses de la question social: une chronique du salariat. Paris: Gallimard, 1993.

CICONELLO, A. O desafio de eliminar o racismo no Brasil: a nova institucionalidade no combate à desigualdade racial. In: OXFAM INTERNATIONAL. (Org.). From Poverty to Power: how Active Citizens and Effective States can Change the World. Oxfam International: Londres, 2008.

COGGIOLA, O. Governo Lula - da esperança à realidade. São Paulo: Xamã, 2004.

DIAS, E. F. Política brasileira: embate de projetos hegemônicos. São Paulo: Instituto José Luís e Rosa Sundermann, 2006.

GLÓRIA, M. C. S. Políticas de ação afirmativa para negros: novas propostas para antigos problemas. Dissertação (Mestrado em Serviço Social) - Programa de Pós-Graduação em Serviço Social, Rio de Janeiro, UFRJ, 2006.

IAMAMOTO, M. V. Serviço Social em tempo de capital fetiche. São Paulo: Cortez, 2007.

A questão social no capitalismo. Temporalis, Brasília, Abepss, ano II, n. 3. p. 9-31, jan./jul., 2001.

LEITE, J. L. Política de assistência estudantil: entre o direito e o favor. Universidade e Sociedade. Brasília: Andes-SN, n. 41, p. 165-173, 2008.

LEITE, J. L. et al. Desfazer os enganos, superar os engodos, resistir e lutar: construir o futuro. In: CONGRESSO DO SINDICATO DOS DOCENTES DAS INSTITUIÇÕES DE ENSINO SUPERIOR, 27, 2008. Goiás. Anexo ao Caderno de Textos. Goiânia: Andes-SN, 2008, p. 10-15.

MOTA, A. E. Cultura de classe e Seguridade Social. São Paulo: Cortez, 2005. 
OLIVEIRA, F. Crítica à razão dualista/O ornitorrinco. São Paulo: Boitempo, 2003.

PASTORINI, A. Quem mexe os fios das políticas sociais? Avanços e limites da categoria 'concessão-conquista'. Serviço Social \& Sociedade. São Paulo: Cortez, v. 18, n. 53, p. 80-101, 1997.

PAULO NETTO, J. A. Capitalismo monopolista e Serviço Social. São Paulo: Cortez, 1992.

Ética e crise dos projetos de transformação social. In: BONETTI, D. A. et al. (Org.). Serviço Social e ética: convite a uma nova práxis. Brasília/São Paulo: CFESS/ Cortez, 1996, p. 21-30.

. conjuntura brasileira: o Serviço Social posto à prova. Serviço Social \& Sociedade. São Paulo: Cortez, Ano XXV, n. 79, p. 5-26, Especial 2004.

ROSANVALLON, P. La nouvelle question sociale repenser l'Etat Providence. Paris: Editions du Seuil, 1995.

SOUZA, D. et al. A política de cotas: breves anotações. In: CONGRESSO DO SINDICATO DOS DOCENTES DAS INSTITUIÇÕES DE ENSINO SUPERIOR, 25, 2006. Mato Grosso. Anexo ao Caderno de Textos. Cuiabá: Andes-SN, 2006, p. 64-67.

VITÓRIA, F. C. D. Cotas raciais: e continuaremos negros.... In: JORNADA INTERNACIONAL DE POLÍTICAS PÚBLICAS, 3, 2007. Maranhão. Anais... São Luís: UFMA, 2007.

Cotas - do direito de todos ao privilégio de alguns. Revista Adunesp Informa. São Paulo: Adunesp, 2004, p. 4.

WOOD, E. Em defesa da história: marxismo e pósmodernismo. Rio de Janeiro: Zahar, 1999.

\section{Notas}

1 Aqui se refere à denominação assumida hodiernamente por alguns partidos políticos e movimentos sociais que, em um retrocesso semântico e político, caracterizam segmentos sociais por suas "especificidades": mulheres, jovens, negros, homossexuais etc. - de "explorados" (vinculação direta à luta de classes), passam a ser "oprimidos" (individualização e vitimização de questões coletivas).

2 “[...] a questão social enquanto parte constitutiva das relações sociais capitalistas é apreendida como expressão ampliada das desigualdades sociais: o anverso do desenvolvimento das forças produtivas do trabalho social. Sua produção/ reprodução assume perfis e expressões historicamente particulares na cena contemporânea. Requer, no seu enfrentamento, a prevalência das necessidades da coletividade dos trabalhadores, o chamamento à responsabilidade do Estadoe 'a afirmação de políticas sociais de caráter universal, voltadas aos interesses das grandes maiorias, condensando um processo histórico de lutas pela democratização da economia, da política, da cultura na construção da esfera pública"' (IAMAMOTO, 2001, p. 1011 , grifos da autora).

3 Expressão usualmente utilizada para designar o liberalismo econômico clássico, ou seja, o modelo que propugna que o Estado deve interferir o menos possível na economia, limitando-se a ofertar bens públicos não interessantes para o mercado, que deve fluir sem amarras.

4 Aquela que envolve uma renda diária per capita de um dólar e que é o principal objeto dos Objetivos do Milênio (FMI e Banco Mundial) para ser erradicada.

5 Alusão ao texto de Vitória (2007).

6 Programa oficial que, sob a justificativa de promover a permanência de cotistas negros nas universidades públicas que adotaram este tipo de sistema para ingresso, na verdade viabiliza farta mão de obra gratuita para a consecução dos programas governamentais. Prevê que as universidades públicas que adotaram o sistema de cotas para alunos negros terão bolsas destinadas a estes, mas elas "[...] estão condicionadas a inserção destes na discussão/investigação sobre as relações existentes entre a epidemia de aids, o racismo, a vulnerabilidade e os direitos humanos"(BRASIL, 2006). Isto quer dizer que a assistência estudantil, que, antes, deveria ser um direito de todo estudante, passa a ser não só condicionada, mas também "privilégio" de alguns alunos em universidades que assumiram um determinado perfil, no caso, o de cotas étnicas.

Janete Luzia Leite

janeteluziaufrj@gmail.com

Doutorado em Serviço Social pela Escola de Serviço Social (ESS) da Universidade Federal do Rio de Janeiro (UFRJ)

Profa. Associada da ESS da UFRJ

\section{ESS - UFRJ}

Av. Pasteur, 250 - Campus Praia Vermelha

Praia Vermelha

Rio de Janeiro - Rio de Janeiro

CEP: 22290-240 